\title{
Construct Validity of the Bidding Game, Binary with Follow-up, and a Novel Structured Haggling Question Format in Determining Willingness to Pay for Insecticide-Treated Mosquito Nets
}

\author{
Obinna Onwujekwe, PhD, Julia Fox-Rushby, PhD, Kara Hanson, ScD
}

\begin{abstract}
This study examines whether making question formats better fit the cultural context of markets would improve the construct validity of estimates of willingness to pay (WTP). WTP for insecticide-treated mosquito nets was elicited using the bidding game, binary with follow-up (BWFU), and a novel structured haggling technique (SH) that mimicked price taking in market places in the study area. The results show that different question formats generated different distributions of WTP. Following a comparison of alternative models for each question format, construct validity was compared using the most consistently appropriate model across question formats for the positive WTP values, in this case, ordinary least squares. Three criteria (the number of statistically significant

explanatory variables that had the anticipated sign, the value of the adjusted $R^{2}$, and the proportion that were statistically significant with the anticipated sign) used to assess the relative performance of each question format indicated that SH performed best and BWFU worst. However, differences in the levels of income, education, and percentage of household heads responding to the different question formats across the samples complicate this conclusion. Hence, the results suggest that the $\mathrm{SH}$ technique is worthy of further investigation and use. Key words: contingent valuation; willingness to pay; construct validity; theoretical validity; question formats; structured haggling technique. (Med Decis Making 2008; 28:90-101)
\end{abstract}

$\mathbf{T}$ he contingent valuation method (CVM) is grounded in welfare economics, with the measurement of consumer surplus providing the major theoretical underpinning. To ascertain the Hicksian surplus or willingness to pay (WTP) empirically, the CVM is

Received 13 October 2003 from the Gates Malaria Partnership, London School of Hygiene and Tropical Medicine, London, UK (OO); Health Policy Research Unit, Department of Pharmacology and Therapeutics, College of Medicine, University of Nigeria, Enugu-Campus (OO); Health Economics Research Group, Brunel University, Uxbridge, UK (JF-R); and the Health Policy Unit, London School of Hygiene and Tropical Medicine, London, UK (KH). We are grateful to Chris Adam, Jonathan Baron, and the anonymous reviewers for their helpful comments. Our thanks also go to the Health Policy Unit, London School of Hygiene and Tropical Medicine, for funding the writing of this article. This study received financial support from the United Nations Development Programme/World Bank/World Health Organization Special Programme for Research and Training in Tropical Diseases. Revision accepted for publication 19 February 2007.

DOI: 10.1177/0272989X07308748 often employed. ${ }^{1}$ Many studies have found that the CVM is a valid technique for valuing the maximum amounts of money that people are willing to pay for health care goods and services. ${ }^{2-6}$ However, critics of the CVM have questioned the validity of stated WTP responses following the identification of bias. ${ }^{6-11}$

The validity of CVM could be enhanced by the use of realistic context-specific contingent valuation questions to elicit WTP. Hence, it is possible that the realism of CVM will be enhanced if the question format mimics the usual type of transaction to which individuals are accustomed. Realistic question formats will decrease the abstract nature of the CVM, stimulate more thought processes that people use in the marketplaces to arrive at their WTP for goods, and encourage respondents to take the valuation more seriously. In the Nigerian context, where most transactions take place in open marketplaces with stalls, the ideal WTP question format would mimic a haggling process. However, it 
is still important to put a face and content-valid measurement to such tests.

One further test of validity in a contingent valuation study is to assess whether hypothesized theoretical relationships between the elicited WTP and its explanatory variables are supported by the data. ${ }^{8}$ Hence, construct validity (also known as theoretical validity) refers to whether the measurement corresponds to theoretical concepts. ${ }^{12}$ If CVM results are valid, the estimated parameters should normally be in accordance with prior expectations. ${ }^{13}$ However, there is no single experiment that can equivocally prove a construct. ${ }^{14}$ One must be able to state several theoretically derived hypotheses involving the particular concept, and construct validity is then established through a pattern of consistent findings. ${ }^{15}$ The assessment of the construct validity of estimates from CVM questioning requires appropriate testing to confirm their accuracy. Most commonly, studies have examined construct validity through modeling of WTP. ${ }^{4,6,16-19\}}$

In this study, we assess the construct validity of WTP elicited for insecticide-treated nets (ITNs) using 3 question formats: bidding game (BG), binary with follow-up (BWFU), and structured haggling technique (SH). The BG is apparently more appropriate than the BWFU in many parts of sub-Saharan Africa such as Nigeria because it mimics to an extent the price-taking mechanisms in open markets there, accounting for its greater use in CVM studies in those countries. ${ }^{20}$ However, SH mimics most closely the usual price-taking mechanism among the Igbo people of Nigeria, and its content validity is improved through observations of trading activities in the marketplace as well as interviews with sellers and buyers of mosquito nets. ${ }^{21}$ The issue of whether improving the context specificity of the question format increases the construct validity of the estimates of WTP is also explored by comparing the construct validity of the different question formats.

\section{METHODS}

\section{Study Area}

The study took place in 3 villages with high malaria transmission rates in the Achi community of Enugu State, southeast Nigeria, in 2000. Achi has an estimated population of 45,000 people and is

Address correspondence to Obinna Onwujekwe, PhD, Health Policy Research Unit, Department of Pharmacology and Therapeutics, College of Medicine, University of Nigeria, Enugu-Campus; telephone/fax: 00234-42-259569; e-mail: onwujekwe@yahoo.co.uk. divided into 12 villages. The people are Igbo, with subsistence farming being the major source of livelihood. This project was the first contact of the villagers with ITNs. Haggling or bargaining for goods is the norm in marketplaces in Achi.

\section{The Goods under Valuation}

ITNs are a new strategy for malaria control in Nigeria. They are private goods that have some limited positive externalities for people close by, and people are expected to pay for them. ITNs kill mosquitoes and other insects, such as bedbugs, and the fact that they also reduce mortality and morbidity due to malaria are additional benefits. ITNs are costeffective interventions for the control of malaria. ${ }^{22}$

\section{Survey Approach}

The sample size was calculated based on an earlier study in Nigeria. ${ }^{21}$ Thus, 300 households were selected from each village using systematic random sampling, by including every 2nd household in the household roster. Each village was composed of approximately 600 households. The household head or the representative (if the household head was not available) from selected households was interviewed. The sample from each village was divided into 3 equal segments, each of which had 1 of the 3 question formats applied to it. This was done to control for differences in village characteristics that might affect the performance of the 3 question formats.

Trained field workers selected from within the study villages administered the pretested questionnaire to the respondents. Each field worker mastered only 1 question format to ensure expertise and proper conduct of the interviews. The questionnaire was used to determine the respondents' maximum WTP for ITNs. Content validity tests with sellers of mosquito nets and consumers were used to select a uniform starting point of 550 Naira (\$5.00) for all question formats. This was based on the average market price of 450 Naira $(\$ 4.10)$ for an ITN plus 100 Naira (\$0.90) to allow for bidding and haggling iterations. Demographic and other information was also collected from respondents. Information on the household's weekly food cost was used as the proxy for income. These variables, their measurement, and the hypothesized theoretical relationships with WTP for ITNs are shown in Table 1. The WTP scenario included showing the respondents an ITN. 
Table 1 The Independent Variables: Measurement and Hypotheses

\begin{tabular}{|c|c|c|}
\hline Variable & Measurement & Hypotheses (Expected Relationship with WTP) \\
\hline Status in the household & $1=$ household head, $0=$ otherwise & $\begin{array}{l}\text { Household heads, being the ones that control } \\
\text { the purse strings, will be more willing to } \\
\text { pay than others }\end{array}$ \\
\hline $\begin{array}{l}\text { Number of household } \\
\text { residents }\end{array}$ & Continuous quantitative measure & $\begin{array}{l}\text { The greater the number, the more willing a } \\
\text { household will be because it will have } \\
\text { more resources to pool }\end{array}$ \\
\hline Gender & $1=$ male, $0=$ female & $\begin{array}{l}\text { Males will be more willing to pay because } \\
\text { they usually control purse strings and are } \\
\text { the key decision makers }\end{array}$ \\
\hline Age & Continuous measure in years & $\begin{array}{l}\text { The active workforce will be more willing to pay } \\
\text { because they have more money; thus, those }>20 \\
\text { years and }<60 \text { years will have more WTP }\end{array}$ \\
\hline $\begin{array}{l}\text { Number of years of formal } \\
\text { schooling }\end{array}$ & Continuous measure in years & $\begin{array}{l}\text { Education increases level of awareness; thus, } \\
\text { increased education will lead to increased } \\
\text { WTP }\end{array}$ \\
\hline Marital status & $1=$ married $0=$ never married & $\begin{array}{l}\text { Married people will be more willing to pay } \\
\text { because they will want to protect their } \\
\text { spouses and children }\end{array}$ \\
\hline $\begin{array}{l}\text { Perceived incidence of } \\
\text { malaria }\end{array}$ & $\begin{array}{l}1=\text { perceives occurrence, } \\
0=\text { perceives no occurrence }\end{array}$ & $\begin{array}{l}\text { If malaria is perceived as likely to occur in a } \\
\text { household, the WTP for a treated net will be } \\
\text { higher }\end{array}$ \\
\hline Actual incidence of malaria & $1=$ had malaria, $0=$ no malaria & $\begin{array}{l}\text { The presence of malaria will be associated with } \\
\text { higher WTP }\end{array}$ \\
\hline $\begin{array}{l}\text { Last month's expenditure to } \\
\text { treat malaria (treatmal) }\end{array}$ & Continuous monetary measure & The greater the expenditure, the more the WTP \\
\hline Dummy of treatmal & $\begin{array}{l}1=\text { made expenditures, } 0=\text { made no } \\
\text { expenditure }\end{array}$ & The greater the expenditure, the more the WTP \\
\hline $\begin{array}{l}\text { Last month's expenditure to } \\
\text { prevent malaria (malprev) }\end{array}$ & Continuous monetary measure & The greater the expenditure, the more the WTP \\
\hline Dummy of malprev & $\begin{array}{l}1=\text { made expenditures, } 0=\text { made no } \\
\text { expenditures }\end{array}$ & The greater the expenditure, the more the WTP \\
\hline $\begin{array}{l}\text { Actual incidence of other } \\
\text { illnesses }\end{array}$ & $\begin{array}{l}\text { Continuous count of occurrence of } \\
\text { other illnesses in past month }\end{array}$ & $\begin{array}{l}\text { This may lead to depletion of household } \\
\text { resources, thereby decreasing WTP }\end{array}$ \\
\hline $\begin{array}{l}\text { Last month's expenditure to } \\
\text { treat other illnesses } \\
\text { (illtreat) }\end{array}$ & Continuous monetary measure & $\begin{array}{l}\text { This may lead to depletion of household } \\
\text { resources, thereby decreasing WTP }\end{array}$ \\
\hline Dummy of illtreat & $\begin{array}{l}1=\text { made expenditures, } 0=\text { made no } \\
\text { expenditure }\end{array}$ & $\begin{array}{l}\text { This may lead to depletion of household } \\
\text { resources, thereby decreasing WTP }\end{array}$ \\
\hline Previous purchase of nets & $\begin{array}{l}1=\text { ever purchased any type of net, } \\
0=\text { otherwise }\end{array}$ & $\begin{array}{l}\text { People who have ever purchased nets will be } \\
\text { more WTP because they had earlier decided } \\
\text { that they are important }\end{array}$ \\
\hline Ownership of radio & $\begin{array}{l}1=\text { household owns a radio, } \\
0=\text { otherwise }\end{array}$ & $\begin{array}{l}\text { This shows enhanced socioeconomic status and } \\
\text { will lead to increased WTP }\end{array}$ \\
\hline Ownership of bicycle & $\begin{array}{l}1=\text { household owns a bicycle, } \\
0=\text { otherwise }\end{array}$ & $\begin{array}{l}\text { This shows enhanced socioeconomic status and } \\
\text { will lead to increased WTP }\end{array}$ \\
\hline $\begin{array}{l}\text { Ownership of grinding } \\
\text { machine }\end{array}$ & $\begin{array}{l}1=\text { owns a grinding machine, } \\
0=\text { otherwise }\end{array}$ & $\begin{array}{l}\text { This shows enhanced socioeconomic status and } \\
\text { will lead to increased WTP }\end{array}$ \\
\hline Ownership of motorcycle & $1=$ owns a motorcycle, $0=$ otherwise & $\begin{array}{l}\text { This shows enhanced socioeconomic status and } \\
\text { will lead to increased WTP }\end{array}$ \\
\hline Ownership of car & $1=$ owns a car, $0=$ otherwise & $\begin{array}{l}\text { This shows enhanced socioeconomic status and } \\
\text { will lead to increased WTP }\end{array}$ \\
\hline $\begin{array}{l}\text { Last week's food cost } \\
\text { (expenditure + home } \\
\text { produced) }\end{array}$ & Continuous monetary measure & $\begin{array}{l}\text { This is the proxy for income; thus, the greater } \\
\text { the food expenditure, the more the WTP }\end{array}$ \\
\hline
\end{tabular}


Table 1 (continued)

\begin{tabular}{|c|c|c|}
\hline Variable & Measurement & Hypotheses (Expected Relationship with WTP) \\
\hline Occupational group 1 & $\begin{array}{l}1=\text { unemployed/unskilled laborer, } \\
0=\text { otherwise }\end{array}$ & $\begin{array}{l}\text { This group will have negative WTP because they } \\
\text { do not have money }\end{array}$ \\
\hline Occupational group 2 & $1=$ farmer, $0=$ otherwise & $\begin{array}{l}\text { This group will have negative WTP because they } \\
\text { lack disposable cash }\end{array}$ \\
\hline Occupational group 3 & $\begin{array}{l}1=\text { skilled laborer/trading } \\
0=\text { otherwise }\end{array}$ & $\begin{array}{l}\text { This group will have a positive WTP because } \\
\text { they have disposable cash }\end{array}$ \\
\hline Occupational group 4 & $1=$ formally employed, $0=$ otherwise & $\begin{array}{l}\text { This group will have a positive WTP because } \\
\text { they have disposable cash }\end{array}$ \\
\hline Occupational group 5 & $\begin{array}{l}1=\text { professionals and medium to } \\
\text { large business, } 0=\text { otherwise }\end{array}$ & $\begin{array}{l}\text { This group will have a positive WTP because } \\
\text { they have disposable cash }\end{array}$ \\
\hline
\end{tabular}

Note: $\mathrm{WTP}=$ willingness to pay.

The scenario is presented in Appendix A, and the 3 question formats are illustrated in Appendix B.

\section{Descriptive Data Analysis}

The data from each question format were pooled across the 3 villages. The demographic and other characteristics of the respondents were tabulated and compared across the 3 question formats using Kruskal-Wallis statistics to assess their similarity. The mean and median WTPs were estimated and compared across the 3 groups using Kruskal-Wallis statistics, Mann-Whitney $U$ test, and median nonparametric test. WTP was expressed in the local currency, the Naira (US\$1.00=110 Naira).

\section{Assessment of Construct Validity}

Following an examination of the bivariate relationships between WTP and independent variables, using ordinary least squares (OLS) regression analyses, further assessment of construct validity required 2 steps: 1st, to determine which type of regression model was appropriate for comparing results across all 3 question formats, and 2nd, to examine the results of the selected model to consider the relative performance of the question formats.

WTP using the full sample was estimated using Tobit, OLS, and a Heckman selection model using a maximum likelihood estimator. For the positive WTP amounts, log OLS and truncated regression models were compared (although in the case of log OLS, the zeros drop out and the equation is effectively estimated on only positive WTP amounts). In the Tobit regression, a logarithm $+1(\log +1)$ transformation was used for WTP estimates starting from zero to ensure that zeros were not treated as missing values after log transformation. ${ }^{19}$ To help determine the most appropriate regression model, results from the Ramsey Regression Equation Specification Error Test (RESET) test, normality test, and tests for heteroskedasticity using generalized residuals were used. The Cook-Weisberg test was also used to check for heteroskedasticity in OLS models, chosen as the most appropriate means for comparing the construct validity of the 3 question formats (authors can be contacted for the full details).

In estimating the OLS models, a full-to-reduced modeling approach was used. Independent variables with the smallest $t$ statistic and whose removal did not either adversely affect the other coefficients or the prediction of the models were removed sequentially. The $F$-test for the hypothesis that the coefficient of that variable is zero was used to decide whether the variable would be dropped (if $F>0.1$ ) or reentered into the regression.

There was no evidence of multicollinearity in the data generated by any of the question formats in distributions for either the full sample or the positive values. The major correlation was between the $2 \mathrm{nd}$ occupational group (subsistence farmers) and 3rd occupational group (skilled laborer/trading) in the BG (0.89), BWFU (0.88), and SH (0.88). The correlation between other pairs of variables was less than 0.70 .

Using results from the OLS regression, the construct validity of different question formats was assessed by comparing WTP estimations using 3 criteria: the number of statistically significant explanatory variables that had the anticipated sign, as an indicator of theoretical validity; the value of adjusted $R^{2}$ as an indicator of the importance of the explanatory model; and the proportion of key variables that were statistically significant with the anticipated signs, as it effectively weights the importance of the relationships. 
The key variables selected a priori were value of food (proxy for income, known to be positively related to the demand for ITNs ${ }^{20}$ and expected, theoretically, to be a normal good), recent experiences with malaria, and gender (because, in this context, women are less likely to purchase health care goods than men). ${ }^{23}$

\section{RESULTS}

\section{Characteristics of the Respondents}

Response rates were $89.0 \%, 91.7 \%$, and $94.0 \%$ for the BG, BWFU, and SH groups, respectively. Nonresponse occurred either because of lack of interest in the project or refusal to answer specific questions. The usable numbers of questionnaires for the analysis were 261, 267, and 273 for the BG, BWFU, and SH groups, respectively.

The principal characteristics shared across each group were that respondents tended to be married, middle-aged, and female, with most respondents being the head of the household (Table 2). Farmers formed the majority of the respondents in the BG and the BWFU groups, whereas they composed $46 \%$ (full sample) and 50\% (positive values sample) of the SH group. A similar result was produced using data from only respondents that stated a positive WTP, with the exception that occupational group 4 (people formally employed) was statistically significantly different across the 3 groups, with the $\mathrm{SH}$ having the highest number of people that were formally employed, followed by the BG, whereas the BWFU had the least. The last column of Table 2 shows the level of uncorrected statistically significant differences in the variables across the 3 groups. The 3 groups of respondents were similar in 10 of the 17 socioeconomic and demographic characteristics, with the main differences including years of education, food value, and occupation.

\section{Descriptive Results of WTP}

Table 3 shows that more than $75 \%$ of the respondents in all 3 groups stated they were willing to pay something for an ITN, with the highest proportion $(80.5 \%)$ from the BWFU group. The decision about being willing to pay anything was not statistically different across the question format groups $\left(\chi^{2}=2.93\right.$, $P=0.231$ ), and the major reason given for not being willing to pay anything for the nets was lack of money.

The mean WTP, using the full sample, was highest in the BWFU group (195.1 Naira; 95\% confidence interval $[\mathrm{CI}]=178.7-211.5)$, followed by the $\mathrm{SH}$ group (190.4 Naira; 95\% CI=170.9 - 209.9), whereas the lowest was in the BG group (162.0 Naira; 95\% $\mathrm{CI}=145.2-178.9)$. These differences in WTP are statistically significantly different at the $1 \%$ level. The median unconditional WTP (positive values) was the same for the BWFU and SH groups at 200 Naira, whereas the BG group had a lower median of 150 Naira $(P<0.15)$. Post hoc tests using the MannWhitney $U$ test showed that there was a statistically significant difference between only the BG and BWFU groups $(P<0.05)$. The $\mathrm{SH}$ group had the highest conditional mean (only positive WTP amounts) WTP at 249.0 Naira, followed by the BWFU group (242.3 Naira) and the BG group (212.8 Naira; $P<0.05$ ). However, the conditional median was the same for all 3 groups at 200 Naira, respectively.

\section{Assessment of the Construct Validity of the WTP Estimates}

Bivariate OLS analysis. Table 4 presents the results of bivariate OLS estimations of relationships of WTP with the independent variables. It shows that in general, many variables were statistically significantly related to WTP in the 3 groups. However, the $\mathrm{SH}$ group had the most statistically significant associations at the $5 \%$ level $(n=16)$ compared with the BG $(n=12)$ and BWFU $(n=9)$ groups. Six variables were positively related to WTP in all 3 groups $(P<0.05)$ : household size, cost of consumed food, being male, respondent having previously purchased a mosquito net, owning a radio, and actual incidence of malaria in the past month. Being a farmer was negatively and statistically significantly related to WTP in the 3 groups $(P<0.05)$. The other statistically significant relationships between the WTP and other independent variables occurred either in pairs or in single-question format groups and are presented in Table 4.

OLS multiple regression analysis. Table 5 presents the OLS estimations for the final and reduced OLS models for the full sample WTP. All models were statistically significant $(P<0.01)$, with the highest level of variation explained in the $\mathrm{SH}$ group $(29 \%)$ compared with the BG (19\%) and BWFU $(20 \%)$ groups. The residuals in the BG and $\mathrm{SH}$ groups were both heteroskedastic, and thus, estimated robust standard errors for the interpretation of the BG and SH models are presented. The residuals in the BWFU were homoskedastic. The results of the Ramsey RESET test indicate no problems of model 

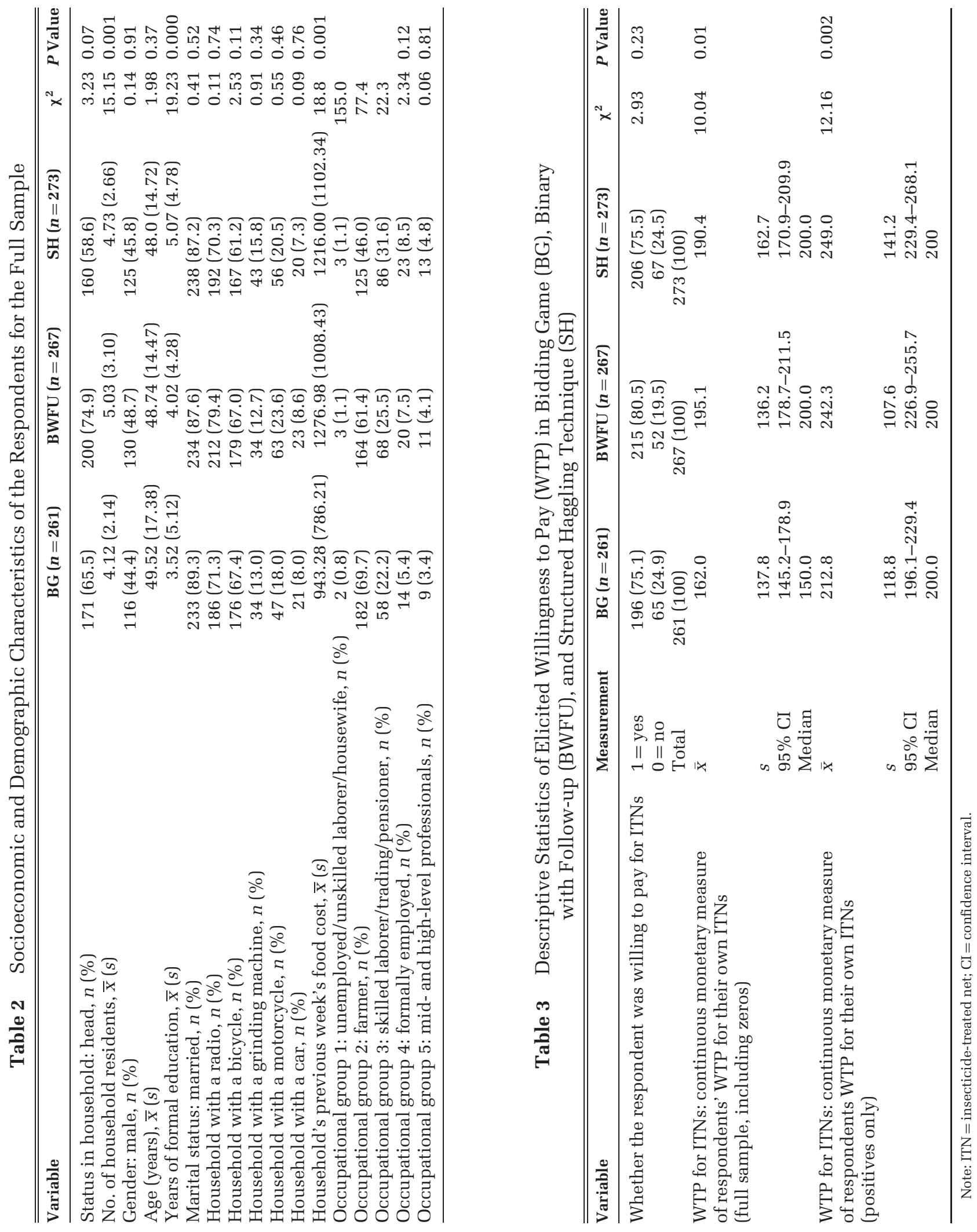
Table 4 Ordinary Least Squares Bivariate Analysis of Willingness to Pay versus Independent Variables in Bidding Game (BG), Binary with Follow-up (BWFU), and Structured Haggling Technique (SH)

\begin{tabular}{|c|c|c|c|c|c|c|}
\hline \multirow[b]{2}{*}{ Variable } & \multicolumn{2}{|c|}{ BG $(n=259)$} & \multicolumn{2}{|c|}{ BWFU $(n=267)$} & \multicolumn{2}{|c|}{ SH $(n=267)$} \\
\hline & Coefficient & SE & Coefficient & SE & Coefficient & SE \\
\hline Status & 22.2 & 17.9 & 20.3 & 19.2 & 68.2 & $19.6^{\text {*ko }}$ \\
\hline Number of household residents & 8.7 & $4.0^{* *}$ & 11.6 & $3.3^{* * k}$ & 16.0 & $3.6^{* 2 * k}$ \\
\hline Gender & 44.5 & $16.7^{* * k}$ & 57.3 & $16.3^{* * k}$ & 83.4 & $19.2^{* * k}$ \\
\hline Age & 0.2 & 0.5 & -1.0 & $0.6^{*}$ & -0.7 & 0.7 \\
\hline School years & 2.6 & 1.7 & 8.9 & $1.9^{* * * k}$ & 9.6 & $2.0^{* * 2 k}$ \\
\hline Marital status & 42.8 & 27.5 & -12.5 & 25.4 & -40.5 & 29.4 \\
\hline Perceived incidence of malaria & 13.1 & 23.5 & 10.5 & 21.9 & 31.2 & 24.3 \\
\hline Actual incidence & 28.9 & $10.8^{* * k}$ & 27.8 & $9.4^{* *}$ & 45.8 & $10.4^{* k *}$ \\
\hline Dummy of expenditure to treat malaria & 26.3 & 17.1 & 29.9 & $16.6^{*}$ & 60.1 & $19.5^{\text {*ke }}$ \\
\hline Dummy of expenditure to prevent malaria & 56.1 & $19.7^{\text {*wok }}$ & 9.2 & 17.8 & 86.9 & $24.7^{\text {*kok }}$ \\
\hline Actual incidence to treat other illnesses & -18.2 & 12.0 & 11.0 & 9.5 & 31.3 & $12.1^{\text {** }}$ \\
\hline Dummy to treat other illnesses & -35.0 & $17.0^{* *}$ & 14.2 & 16.9 & 46.3 & $21.6^{* *}$ \\
\hline Previous purchase of net & 55.9 & $23.2^{* *}$ & 54.7 & $22.7^{* *}$ & 78.6 & $27.8^{* k * k}$ \\
\hline Ownership of radio & 52.7 & $18.6^{* * * k}$ & 78.1 & $20.1^{*+*}$ & 112.2 & $20.5^{\text {*to }}$ \\
\hline Ownership of bicycle & 30.5 & $18.1^{*}$ & 28.1 & 17.7 & 30.5 & 20.2 \\
\hline Ownership of grinding machine & 73.1 & $25.0^{* * * k}$ & 6.0 & 25.1 & 103.4 & $26.3^{\text {*wo }}$ \\
\hline Ownership of motorcycle & 51.0 & $22.0^{* *}$ & 18.5 & 19.6 & 20.2 & 24.4 \\
\hline Ownership of car & -44.2 & 31.3 & 32.0 & 29.7 & 97.2 & $37.4^{* *}$ \\
\hline Food cost & 62.4 & $11.4^{* * k}$ & 50.2 & $10.3^{* * k}$ & 82.4 & $9.8^{* w k}$ \\
\hline $\begin{array}{l}\text { Occupational group 1: unemployed/unskilled } \\
\text { laborer/housewife }\end{array}$ & 13.7 & 98.1 & -113.0 & 78.9 & 144.5 & 94.1 \\
\hline Occupational group 2: farmer & -41.7 & $18.4^{\text {** }}$ & -54.1 & $16.8^{\text {*ak }}$ & -51.7 & $19.6^{\text {*wk }}$ \\
\hline $\begin{array}{l}\text { Occupational group 3: skilled laborer/trading/ } \\
\text { pensioner }\end{array}$ & 51.8 & $20.3^{* *}$ & 74.5 & $18.6^{* * k}$ & 14.9 & 21.2 \\
\hline Occupational group 4: formally employed & -8.3 & 38.0 & -2.5 & 31.7 & 25.7 & 35.5 \\
\hline $\begin{array}{l}\text { Occupational group 5: mid- and high-level } \\
\text { professionals }\end{array}$ & 74.5 & 46.6 & -59.3 & 41.9 & 119.1 & $45.7^{\text {** }}$ \\
\hline
\end{tabular}

${ }^{*} P<0.10 .{ }^{*} P<0.05$. ${ }^{* * * *} P<0.01$.

specification across the 3 question formats. Two and 6 cases in the BG and SH, respectively, had some missing values on some of the explanatory variables, accounting for the slightly reduced numbers of observations in the multiple regression analysis.

Table 5 shows that, excepting the constant, 3 of 4 of the statistically significant variables (at the $5 \%$ level) in the BG group had the hypothesized signs (3 of 5 in the BWFU group and 4 of 4 in the SH group). At the $10 \%$ level of significance, the performance of the $\mathrm{SH}$ and $\mathrm{BG}$ are equal, with the BWFU remaining the worst performing.

All 3 key variables had the expected sign in each question format. Food cost was statistically significant (at the 1\% level) in all 3 models and showed that a $1 \%$ increase in the cost of food would lead to an increase in WTP by 0.54 Naira, 0.30 Naira, and 0.49 Naira in the BG, BWFU, and SH groups, respectively. However, gender was not statistically significant in any model. Only in the SH model was actual incidence of malaria significant at the $5 \%$ level, indicating that having a case of malaria within the household in the past month would increase WTP by 36.2 Naira.

Considering other variables, the BG model showed that incurring any expenditure to prevent malaria or ownership of a grinding machine increases WTP by 66.7 Naira in both cases. The economic effect of the number of years of schooling was considerable in the BWFU model, with each successive year in education contributing to an increase in WTP of 9 Naira. In this same model, those who were formally employed or who were at least mid- or high-level professionals were associated with a substantial drop in WTP of 98.4 Naira and 135.9 Naira compared with unemployed people, students, or full-time housewives. In both the BWFU and SH, ownership of a radio was associated with an increased WTP of 42.7 Naira in the BWFU group and 49.0 Naira in the SH group. 


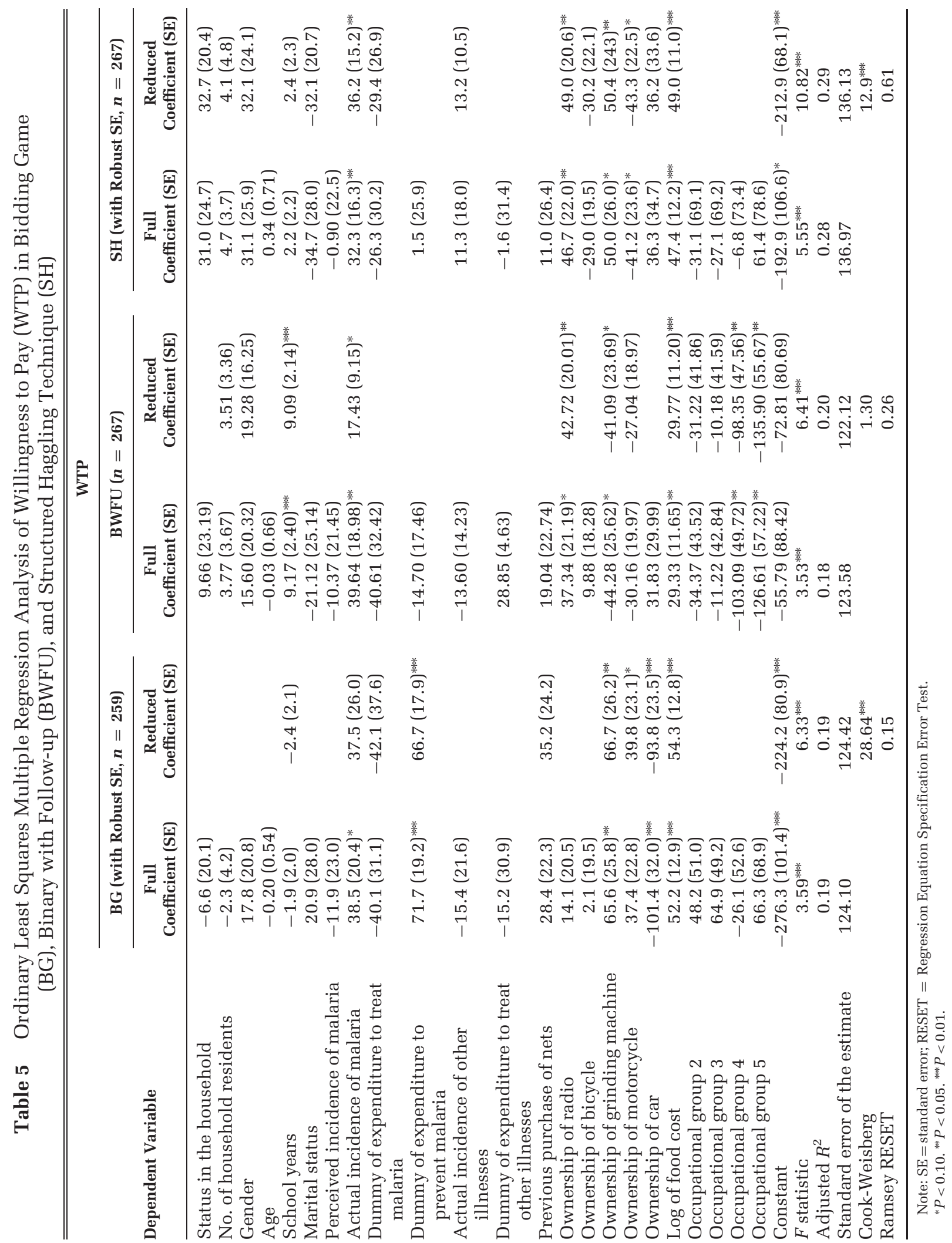


Some variables in the reduced OLS models did not match anticipated relationships at the $5 \%$ level (e.g., in the BG group, ownership of car, and in the BWFU group, occupation). At the most conservative level of $10 \%$, ownership of a grinding machine (in BWFU) and ownership of a motorcycle (SH) also did not match expected signs. Comparing results across all 3 models, the least robust explanatory variables appear to be ownership of a grinding machine or motorcycle, which switch both sign and significance across models.

\section{DISCUSSION}

We discuss 2 questions: Is there evidence of the validity of the WTP technique per se in this context, And is there any evidence that SH performs better, or at least no worse than, either BG or BWFU? Finally, we reflect on the processes through which the construct validity of WTP is and can be assessed.

Overall, the tests indicate that the CVM was reasonably valid in the study setting. The relationships between WTP and many of the variables used in both the bivariate analysis and the multiple regression analysis models were consistent with those anticipated from demand theory. In particular, WTP was consistently found to be positively and significantly related to income (proxied by food cost). Other studies have also found that WTP is associated with the ability to pay. ${ }^{24}$ Such an association means that WTP is behaving in a way that would be expected a priori, thus confirming the internal validity of the technique. ${ }^{25}$ Also as expected, our a priori key variables of both male gender and actual incidence of malaria were positively related to WTP.

Although the results are encouraging, there are several reasons for continued caution. First, because the study was not designed in such a way that a starting-point bias could be tested, it is possible that such a bias affected the findings, especially with respect to BG and $\mathrm{SH}$. However, a previous study in this part of Nigeria found no evidence of a startingpoint bias. ${ }^{20}$ Second, many of the variables that were hypothesized to influence WTP were not statistically significant in the regression analysis or had signs that differed from expectations (although few were also statistically significant). However, many of them were statistically significant in the bivariate analysis. In addition, the study was not set up to assess sensitivity to quantity or quality; hence it is not clear whether WTP would be greater for more nets or for nets that last longer.
The relatively low WTP values compared with the cost of an ITN could indicate that people lack sufficient income to pay more for ITNs in this area, as was found in Kenya. ${ }^{26}$ Alternatively, respondents could have low private values for ITNs or have given strategic responses. If all respondents were responding strategically (e.g., if they felt their responses would influence future prices charged for ITNs), then the entire distribution of WTP would shift downward, and the hypothesized relationship with the ability to pay would still be observed in the data. It is also possible that some people were anchoring their WTP responses to the value of ordinary (untreated) nets, which cost less than ITNs in the markets.

\section{Comparison of Validity across Question Formats}

The average maximum WTP elicited by $\mathrm{SH}$ was comparable to that of BWFU and more than that of BG. However, many key variables, such as the cost of food and recent incidence of malaria, were uniformly statistically significant in the 3 question formats. Therefore, on the basis of convergence with other question formats, it appears that $\mathrm{SH}$ is at least an equally valid method for eliciting maximum WTP.

Using the 3 criteria set out in the Methods section shows that the OLS model for SH explains the greatest amount of variation in WTP (as measured by the adjusted $R^{2}$ ) and that it was the only model in which statistically significant variables at the $5 \%$ level all had the expected sign. However, the BG method had most statistically significant variables appearing with the anticipated sign. The 3rd criterion also indicated a best position, as the SH method showed more of the key variables to be statistically significant and with the expected sign. This suggests that our evidence supports the use of the SH method over other elicitation methods.

In comparing the 3 different question formats, "it is necessary to establish that differences in WTP elicitation using different methods are due to the different stimuli, and not due to external factors." 27 The 3 groups used for the questionnaire survey were reasonably similar in terms of socioeconomic and demographic characteristics. In particular, gender was not statistically significantly different, and this is important because women usually state lower prices for health goods. ${ }^{28}$ However, groups differed according to the value of the previous week's food, with the BG group having a much lower value than the BWFU and SH groups. Despite this, both the $\mathrm{SH}$ and BG groups had very similar-sized coefficients 
for log food cost, indicating that a $1 \%$ rise in food cost was associated with a 0.49 to 0.54 Naira rise in WTP. It is also possible that differences in the education of the respondent and whether he or she was the household head contribute to differences between the samples and hence their WTP and ensuing explanatory models.

Studying the models more closely suggests that BWFU is marginally less valid because the occupation variable, in particular, is not performing as expected. However, it is possible that this could be a function of the variable itself rather than the question formats.

It is not very surprising that the effect of ownership of some assets (e.g., grinding machine and motorcycle) appears to operate differently across the regression analysis models for the question formats. For instance, although asset ownership may reflect past rather than current economic status, there is no obvious reason for a differential effect in the 3 groups. However, this may not be too serious an issue for robustness, as the grinding machine was positively related to WTP at the $5 \%$ level in 2 reduced models and ownership of a motorcycle never reached significance at less than the 10\% level.

There are a number of possible reasons for the inconsistencies in the results. One is that the basis for the theoretical expectations of the signs of some variables is less robust than for the other indicators of need and of socioeconomic status. Alternatively, it could be due to challenges in measuring socioeconomic status. For example, we have used food expenditure and a series of asset variables, but there may be multicollinearities among these variables that are not picked up in simple bivariate correlation coefficients. A 2nd issue is the number of variables that were not significant in the regressions. This could also be due to measurement error, which would tend to bias the coefficients toward the null. It has been argued that there is no fool-proof procedure for determining which 1 (or more) of these interpretations of negative evidence is correct in any given instance and that it is the total configuration of empirical evidence that lends credence to one interpretation over another. ${ }^{24}$

\section{Reflections on the Process of Establishing Construct Validity}

This article posited 3 criteria in a structured format for examining construct validity. Over time, we have continued to debate the importance of the 3 criteria. Using $R^{2}$ and showing that a model that fits the data better (i.e., a better specification and higher $R^{2}$ ) may not necessarily imply that the process generating the data is superior per se. If this is the case, construct validity can be considered only with respect to whether WTP has the predicted theoretical relationship or predicts actual behavior better. The importance of correctly specifying expected relationships then becomes paramount. The development of new measures, such as $\mathrm{SH}$, or the application of old measures in new contexts (such as application in another country or to a different disease/intervention) must increase the uncertainty with which previously tested hypotheses are held. These uncertainties are magnified further if there are any concerns about the way explanatory variables such as income or marital status are measured. Nevertheless, despite these real concerns, to be uncertain about hypotheses and yet use the same variables as an indicator of construct validity is akin to both having our cake and eating it. We attempted to address this by specifying that some variables were of greater importance and, implicitly, that some hypotheses were stronger than others. In this case, our hypotheses were largely upheld, and therefore, supporting evidence toward establishing construct validity of each method was provided.

With hindsight, it strikes us that such an approach is open to abuse and that perhaps credibility could be lent to the process of developing any outcome measure by specifying and justifying expected relationships publicly in advance, with any changes to thinking documented only on the basis of relevant new evidence. Such an approach might then begin to resemble the testing of a new intervention.

\section{CONCLUSION}

All 3 approaches to eliciting WTP demonstrated some degree of construct validity. Our results suggested that the $\mathrm{SH}$ approach, which has better face and content validity than the BG and BWFU approaches, also performed better on all 3 criteria set to investigate construct validity. The BWFU was least convincing because of the unexpected direction of the occupation variable. We therefore recommend that other investigators consider testing the SH technique in settings in which haggling is the more usual approach to setting prices. It would be interesting to supplement further testing with debriefing interventions to ascertain what factors participants think might increase or decrease WTP values as well as 
undertake some think-aloud interviews to hear some of the thought processes by which they arrive at their WTP response. One possible implication is that the number of iterations in a $\mathrm{SH}$ might need to change.

\section{APPENDIX A} Scenario

As you may be aware, mosquito coils, insecticide sprays, herbs, and so forth are some of the ways used to prevent mosquito bites. Another method of preventing mosquitoes from biting people is through the use of ordinary mosquito nets. A form of these nets is mosquito bed nets. A problem with these ordinary nets is that mosquitoes still perch on them to bite people sleeping inside. Also, these ordinary nets neither kill nor chase away mosquitoes. However, there is a new method of treating mosquito nets with special chemicals. These treated nets are called insecticide-treated nets (ITNs). They chase away and kill mosquitoes. They also ensure that the mosquitoes do not perch on the nets to bite somebody sleeping inside. These are as a result of the chemicals used to treat the nets. Studies around the world have shown that these treated nets can reduce the number of times one gets malaria. These nets also get rid of other insects such as bed bugs, lice, and so on. [Stop and ask the respondent: Is the difference between simple and ITNs clear to you, together with the advantages of ITNs?]

The chemicals used to treat the nets are harmless to both adults and children. However, mild side effects of the insecticides occur mostly in the 1st week of use of the ITNs. These side effects may make the person to feel that he or she has a common cold. These occur especially on direct contact with the nets, but thereafter, there would be no symptoms after the 1st week. These side effects do not occur in everybody using the nets but only in a few people; about 1 out of 50 people. However, common drugs such as paracetamol easily cure the side effects. [Stop and ask the respondent: Do you have any questions?]

The nets, however, need at least yearly retreatment with the chemicals to maintain their effectiveness. This net retreatment will be organized by a committee to be selected from your community in conjunction with the Enugu State Malaria Control Unit. Individual households can also buy the chemicals and retreat their nets after receiving a small training. You will have to pay for the net retreatment. [Stop and ask the respondent: Do you have any questions?]
It is a fact that most households spend a lot of money either treating or preventing malaria. The sufferers and people looking after them also lose valuable work hours and school hours. Thus, the treated nets will ultimately reduce the time lost due to malaria and constant money spent to treat it in your household.

We have a program to bring the treated nets to your community and hope that you can purchase them for both yourself and other members of your household. This is because the nets will not be given free of charge. The bed nets will be sold only to those who have offered to pay enough money to cover the price of the nets. Trained community members will sell the treated nets at either central locations in your community and/or door to door. The sales will commence within 1 month from the end of this interview. You can make weekly installment payments, but total payments should be made in a maximum period of 1 month. You shall receive the nets after you have fully paid. However, the cash-and-carry system is encouraged.

\section{APPENDIX B \\ Question Formats Used to Elicit Willingness to Pay}

\section{Bidding Game Format}

1. Are you willing to pay 550 Naira for a treated net? $1=$ yes (Q2), $0=$ no (Q3)

2. What if the price is 650 Naira, would you be willing to pay? (Interviewer: No matter what the answer is, go to Q4.)

3. What if the price is 450 Naira, would you be willing to pay? (Interviewer: No matter what the answer is, go to Q4.)

4. What is the maximum amount you are willing to pay for a treated net?

\section{Binary with Follow-up Format}

1. Are you willing to pay 550 Naira for a treated net? $1=$ yes (Q2), $0=$ no (Q2)

2. What is the maximum amount you are willing to pay for a treated net? (Interviewer: if the amount is less than 450 Naira, go to Q3.)

3 . The actual price of the treated net is 450 Naira for 1 ; are you willing to buy at this price? $1=$ yes, $0=$ no 


\section{Structured Haggling Technique Format}

1. The price of a treated net is 550 Naira; are you willing to pay? $1=$ yes (Q7), $0=$ no (Q2), do not know (Q2)

2. What is the maximum amount you are willing to pay? (Interviewer: if greater than or equal to 450 Naira, go to Q3, but if less than 450 Naira, go to Q4.)

3. What if the price is 540 Naira, would you be willing to pay? $1=$ yes, $0=$ no (Interviewer: no matter what the answer is, go to Q7.)

4. What if the price is 490 Naira, would you be willing to pay? $1=$ yes (Q7), $0=$ no (Q5)

5 . What really is the maximum amount you are willing to pay for a treated net? (Interviewer: If greater than or equal to 450 Naira, go to Q7, but if less than 450 Naira, go to Q6.)

6 . The amount that you have quoted is too low and cannot cover the cost of the treated net, and so you will have to increase the amount if you really want to buy the treated net. So what is the final maximum amount you are willing to pay for a treated net? (Interviewer: No matter what the answer is, go to Q7.)

7. If, due to inflation or other uncertainties, the price of the treated net increases, what is the maximum amount you are very certain to pay?

\section{REFERENCES}

1. Golan EH, Shechter M. Contingent valuation of supplemental health care in Israel. Med Decis Making. 1993;13(4):302-10.

2. O’Brien B, Goeree R, Gafni A, et al. Assessing the value of a new pharmaceutical: a feasibility study of contingent valuation in managed care. Med Care. 1998;36(3):370-84.

3. Corso PS, Hammitt JK, Graaham JD, Dieker RC, Goldie SJ. Assessing preferences for prevention versus treatment using willingness to pay. Med Decis Making. 2002;22(suppl):S92-101.

4. Foreit JR, Foreit KG. The reliability and validity of willingness to pay surveys for reproductive health pricing decisions in developing countries. Health Policy. 2003;63(1):37-47.

5. Lenert LA. Use of willingness to pay to study values for pharmacotherapies for migraine headache. Med Care. 2003;41(2):299-308.

6. Mitchell RC, Carson RT. Using Surveys to Value Public Goods: The Contingent Valuation Method. Washington (DC): Resources for the Future; 1989.

7. Diamond P, Hausman J. Contingent valuation: is some number better than no number? J Econ Perspect. 1994;8(4):45-64.

8. Stavem K. Association of willingness to pay with severity of chronic obstructive pulmonary disease, health status and other preference measures. Int J Tuberc Lung Dis. 2002;6(6):542-9.

9. Baron J. Biases in the quantitative measurement of values for public decisions. Psychol Bull. 1997;122:72-88.

10. Currie GR, Donaldson C, O’Brien BJ, Stoddart GL, Torrance GW, Drummond MF. Willingness to pay for what? A note of alternate definitions of health care program benefits for contingent valuation studies. Med Decis Making. 2002;22(6):493-7.

11. Shackley P, Donaldson C. Should we use willingness to pay to elicit community preferences for health care? New evidence from using a "marginal" approach. J Health Econ. 2002;21(6):971-91.

12. Klose T. The contingent valuation method in health care. Health Policy. 1999;47:97-123.

13. Asgary A, Willis KG. Estimating the benefits of construction measures to mitigate earthquake risks in Iran. Environ Plann B Plann Des. 1997;24(4):613-24.

14. Streiner DL, Norman GR Health Measurement Scales: Practical Guide to Their Development and Use. 2nd ed. New York: Oxford University Press; 1995.

15. Carmines EG, Zeller RA. Reliability and Validity Assessment. London: Sage; 1979.

16. Luchini S, Protiere C, Moatti JP. Eliciting several willingness to pay in a single contingent valuation survey: application to health care. Health Econ. 2003;12(1):51-64.

17. Gyldmark M, Morrison GC. Demand for health care in Denmark: results of a national sample survey using contingent valuation. Soc Sci Med. 2001;53(8):1023-36.

18. Dalmau-Matarrodona E. Alternative approaches to obtain optimal bid values in contingent valuation studies and to model protest zeros: estimating the determinants of individual's willingness to pay for home care services in day care surgery. Health Econ. 2001;10:101-18.

19. Donaldson C, Jones AM, Mapp TJ, Olson JA. Limited dependent variables in willingness to pay studies: applications in health care. Appl Econ. 1998:30;667-77.

20. Onwujekwe OE, Nwagbo DFE. Investigating starting-point bias: a survey of willingness to pay for insecticide-treated nets. Soc Sci Med. 2002;55(12):2121-30.

21. Onwujekwe OE, Chima R, Shu E, Nwagbo D, Okonkwo P. Hypothetical and actual willingness to pay for insecticide-treated nets: a study in five Nigerian communities. Trop Med Int Health. 2001;6(7):545-53.

22. Goodman CA, Mnzava AE, Dlamini SS, Sharp BL, Mthembu DJ, Gumede JK. Comparison of the cost and cost-effectiveness of insecticide-treated bednets and residual house-spraying in KwaZulu-Natal, South Africa. Trop Med Int Health. 2001;6(4):280-95.

23. Johannesson M, Jonsson B, Borgquist L. Willingness to pay for anti-hypertensive therapy: results of a Swedish pilot study. J Health Econ. 1991;10(4):461-74.

24. Hoddinott J. Modelling remittance flows in Kenya. J Afr Econ. 1992;1(2):207-32.

25. Donaldson C, Farrar S, Mapp T, Walker A, McPhee S. Assessing community values in health care: is the "willingness to pay" method feasible? Health Care Anal. 1997;5:7-29.

26. Guyatt HL, Ochola SA, Snow RW. Too poor to pay: charging for insecticide-treated bednets in highland Kenya. Trop Med Int Health. 2002;7(10):846-50.

27. Loomis J, Brown T, Lucero B, Peterson G. Improving validity experiments of contingent valuation methods: results of efforts to reduce the disparity of hypothetical and actual WTP. Land Econ. 1996;72:450-61.

28. Brieger WR, Ramakrishna J, Adeniyi JD. Community response to social marketing: filters for guinea worm control. Int Q Community Health Educ. 1989-1990;19(1):3-17. 